\title{
IMPLANTAÇÃO DE METODOLOGIA DE GESTÃO DE SOBRESSALENTES COMO FATOR DE REDUÇÃO DE CUSTOS DE MANUTENÇÃO E AUMENTO DE CONFIABILIDADE DOS ATIVOS*
}

\section{Resumo}

Ricardo Tadeu Meneses Sodré José Sérgio Brandão Leal

O mercado siderúrgico vive nos últimos anos um de seus maiores desafios de toda história. As empresas buscam, a todo instante, formas de redução de custo visando a manutenção da operação dos seus ativos. A gestão eficiente de estoques é parte fundamental para a redução de custos e garantia da segurança das operações da empresa. Para a classificação da criticidade dos sobressalentes não existe um critério claro e bem definido. Outro ponto importante é que sobressalentes realmente importantes podem não estar contemplados no estoque. O trabalho estabelece um modelo para melhorar a gestão de sobressalentes na ArcelorMittal Tubarão incluindo a correta identificação dos sobressalentes críticos, a priorização desses sobressalentes com foco no que deve ser comprado imediatamente e o que podemos postergar, a reclassificação dos sobressalentes de manutenção quanto a sua criticidade e à criação de alternativas para gerenciar e manter nos estoques os sobressalentes realmente críticos e dispor/criar alternativas para os sobressalentes não críticos. Essa nova metodologia foi aplicada como piloto na Linha de Acabamento e Linha de Tesoura da ArcelorMittal Tubarão indicando ganhos expressivos.

Palavras-chave: Sobressalentes, Criticidade, Gestão.

\section{DEPLOYMENT OF SPARE MANAGEMENT METHODOLOGY AS MAINTENANCE COST REDUCTION FACTOR AND ASSET RELIABILITY INCREASE}

\begin{abstract}
In recent years the steel market lives one of its greatest challenges throughout history. Companies seek, at all times, cost reduction ways in order to keep the assets operation. Efficient inventory management is a key part to reduce costs and to ensure the company's operations safety. In terms of spares, for criticality classification, there are no clear and well-defined criteria. Another important point is that really important spare could be forgotten. This work establishes a model to improve the ArcelorMittal Tubarão spare parts management including the correct identification of critical spares, prioritization focusing on what should be purchased immediately and what can we delay, the reclassification of maintenance spare as their criticality and the creation of alternatives to manage and keep stocked only the critical ones and create alternatives to non-critical spares. This new methodology was applied as a pilot project on ArcelorMittal Tubarão Finishing and Dividing Line indicating significant gains.
\end{abstract}

Keywords: Spare parts; Criticality; Management.

1 Engenheiro Mecânico, Esp. em Engenharia de Manutenção, de Materiais e em Administração, Mestre em Fadiga e Mecânica de Fratura, Coordenador de Confiabilidade, ArcelorMittal Tubarão, Vitória/ES, Brasil.

2 Engenheiro Mecânico, Esp. em Administração, Gerente de Área de Manutenção do Refino de Aço, ArcelorMittal Tubarão, Vitória/ES, Brasil. 


\section{INTRODUÇÃO}

De uma maneira macro a Manutenção de Classe Mundial consiste na melhoria de modo constante e estruturado, com foco em estar ou se manter no primeiro quartil das melhores empresas do mundo.

O desenvolvimento da manutenção na busca da excelência ou Classe Mundial passa pela identificação e adequação das melhores práticas. Isso significa modificar a forma de atuar. No entanto, essas modificações demandam tempo. Um programa de melhoria da manutenção, consistente e aplicado com disciplina demanda um tempo entre 3 e 5 anos para que se atinja a excelência. Além disso, deve ser um programa institucional, requer aplicação de recursos, deve ser sistematicamente avaliado por equipe de auditoria interna e externa [1].

Neste contexto a manutenção deve garantir a disponibilidade da função dos equipamentos e instalações (ativos) de modo a atender a um processo de produção, com confiabilidade, segurança, preservação do meio ambiente e custo-eficiente. Com isso a visão de simplesmente "Realizar Manutenção" cede lugar a "Garantia da Disponibilidade e Redução da Variabilidade", e a missão deverá ser de "Produzir Resultados Custo-eficiente" ao invés de "Reduzir Custos" [2].

A gestão estratégica de estoques de sobressalentes de manutenção é parte fundamental da gestão estratégia da manutenção na busca da excelência. Estoques de sobressalentes para equipamentos correspondem a uma aplicação específica na administração de materiais, especialmente devido às suas características peculiares, ligadas a sua finalidade e importância técnica e financeira para o negócio como um todo. A boa gestão dos estoques de sobressalentes culmina em redução de custos, que indubitavelmente, são fontes de vantagens competitivas. A busca por custos baixos se constitui em uma das três estratégias competitivas que as empresas podem seguir, juntamente com as estratégias de diferenciação e enfoque. Mesmo nas outras estratégias os custos não podem ser desconsiderados [3,4].

Embora exista a consciência de que a gestão de inventários de peças sobressalentes se diferencie da gestão de produtos em processo ou acabados, a variável chave de decisão do gestor de materiais é a mesma, ou seja, definir o índice ótimo de reposição do seu estoque. Ainda segundo o autor, estoques insuficientes de sobressalentes podem levar a uma parada prolongada (e indesejada) do equipamento, todavia, "a manutenção de seu estoque excessivo leva a grandes custos de transporte, além de ocultar ou encobrir problemas básicos que causam a necessidade de peças de reposição, numa primeira análise". O excesso de estoque, também, leva a uma chance maior desses bens deteriorarem, tornarem-se obsoletos ou apenas se perderem, além disso, ocupam espaços físicos e elevam o custo de armazenamento [5].

A gestão das peças sobressalentes consiste em encontrar respostas viáveis e eficientes para três perguntas básicas: Quais peças devem ser estocadas? (a); Onde devem ser estocadas? (b); quantos itens de cada peça devem ser estocados (definir nível e quantidade de ressuprimento)? (c). O estoque de sobressalentes está intimamente ligado ao balanço entre os custos da falta, do excesso e do ressuprimento, bem como à política adotada pela empresa.

Não há duvidas que altos níveis de estoques escondam sérios problemas gerenciais das empresas. Contudo, a redução de estoque não tem um fim em si mesmo, mas é uma consequência do processo de melhoria contínua da produção. Deve-se ter cuidado ao apelo financeiro proporcionado pela diminuição de estoques de sobressalentes. Esses devem ser reduzidos gradualmente, forçando a organização 
buscar aumentos de produtividade (redução de falhas). Concomitantemente, é fundamental ter sob controle os custos de aquisição de sobressalentes, os riscos de faltas e a garantia da estabilidade operacional [6].

\subsection{Entendendo as consequências das falhas}

Existem várias consequências de falhas e usualmente elas são classificadas como segurança, meio ambiente ou econômica. Algumas falhas capazes de ferir ou matar alguém são completamente inaceitáveis a qualquer custo. Outros tipos de falhas que além de ceivar vidas humanas envolvem grandes perdas financeiras também são inaceitáveis.

Em quase todos os casos, após a avaliação e eliminação das consequências relativas à segurança e meio ambientes serem eliminadas, todas as outras consequências podem ser mensuradas em termos financeiros, incluindo, lucrocessante, custo de oportunidade e custo do reparo (mão de obra e materiais) [7].

Sob um ponto de vista de gestão de risco, a avaliação não pode considerar apenas o custo do sobressalente versus as consequências das falhas. A correta avaliação e gestão de risco deve, necessariamente, levar em consideração a probabilidade de ocorrência da falha, ou seja:

Risco = Custo da falha $\times$ Probabilidade de Ocorrência (1)

Se o valor monetário do sobressalente em questão for maior que o valor monetário do risco, o sobressalente em questão não deve ser adquirido. Porém se o se o valor monetário do sobressalente em questão for menor que o valor monetário do risco, 0 sobressalente em questão deve ser incluído no orçamento para compra.

Tendo os sobressalentes corretos ajuda a manter as consequências das falhas em nível gerenciável. Esse é o mesmo pensamento utilizado quando o seguro é contratado. $O$ valor cobrado pelo seguro leva em consideração a probabilidade de ocorrência do sinistro versus o custo do sinistro em questão. Essas considerações são à base de raciocínio para a gestão de riscos de ativos.

A atual visão de risco atrelado ao estoque de sobressalentes da ArcelorMittal Tubarão leva em consideração o "Índice de falta e segurança do material" que atende as seguintes condições:

- $\quad$ Y00 - Estratégico - Quando caracteriza que o item deve existir estoque para garantir a disponibilidade operacional, cuja falta caracteriza uma situação grave para a empresa.

- Y01 - Paralisa a Produção - Quando caracteriza o nível de criticidade do item, podendo ele paralisar a produção com relação a sua área de aplicação.

- Y02 - Afeta a Produção - Quando caracteriza o nível de criticidade do item, podendo ele afetar a produção com relação a sua área de aplicação.

- $\quad$ Y03 - Não Afeta a Produção / Possui Alternativas - Quando caracteriza o nível de criticidade do item, sendo que ele não afeta a produção e possui alternativas com relação a sua área de aplicação.

Fica a cargo da pessoa que está preenchendo o cadastro do item de sobressalente no sistema fazer a definição do "Índice de falta e segurança do material" baseado nas definições citadas acima, bem como a definição do planejamento de necessidade do material: 
- $\quad$ YD - Just in time (Estoque nulo) - Quando não é necessário manter o material imobilizado no estoque, sendo previsível a sua necessidade de compra a partir da Requisição de Material.

- $\quad$ V1 - Ponto de reabastecimento manual - Quando o material é de consumo não frequente, eventual e é necessário definir alguma quantidade mínima no estoque e definição de parâmetros de ressuprimento indicados de forma manual.

- V2 - Ponto de reabastecimento automático - Quando o material é de consumo frequente sendo possível mantê-lo em estoque com uma determinada rotatividade, e com definição dos parâmetros de ressuprimento indicados de forma automática pelo sistema.

- $\quad$ ND - Quando o material não necessita de gestão, apenas sendo tratado por exceção quando houver uma Requisição de Material.

Outro ponto importante é que os sobressalentes realmente importantes para a garantia operacional podem não estar contemplados no estoque definido para a área operacional.

O presente trabalho estabelece um modelo para melhorar a gestão de sobressalentes na ArcelorMittal Tubarão incluindo a correta identificação dos sobressalentes críticos, a priorização desses sobressalentes críticos com foco no que deve ser comprado imediatamente e o que podemos postergar, a reclassificação dos sobressalentes de manutenção em Y00, Y01, Y02 e Y03 levando em consideração a criticidade dos equipamentos, o lead time e o custo do sobressalente e à criação de alternativas para gerenciar e manter nos estoques os sobressalentes realmente críticos e dispor/criar alternativas para os sobressalentes não críticos. Essa nova metodologia foi aplicada como piloto na Linha de Acabamento e Divisão de Bobinas indicando ganhos expressivos.

Essa nova metodologia será aplicada como piloto na Linha de Acabamento (LA) e Linha de Tesoura (LT) indicando o potencial de redução de custos com sobressalentes com garantia da confiabilidade.

\section{MATERIAIS E MÉTODOS}

O trabalho visa estabelecer uma melhor gestão de sobressalentes na ArcelorMittal Tubarão seguindo quatro passos principais:

\subsection{Identificação dos sobressalentes críticos através da aplicação da metodologia RCM - Manutenção Centrada em Confiabilidade}

É fundamental garantir que os sobressalentes necessários para a garantia operacional dos equipamentos sejam devidamente identificados. A identificação passa inicialmente por recomendações dos fabricantes, principalmente para os primeiros anos de operação, e por análises mais aprofundadas utilizando ferramentas como a Manutenção Centrada em Confiabilidade - RCM (ReliabilityCentered Maintenance).

Manutenção Centrada na Confiabilidade é um processo usado para determinar o que precisa ser feito para assegurar que qualquer item físico continue a cumprir as funções desejadas no seu contexto operacional atual, Figura 1. 

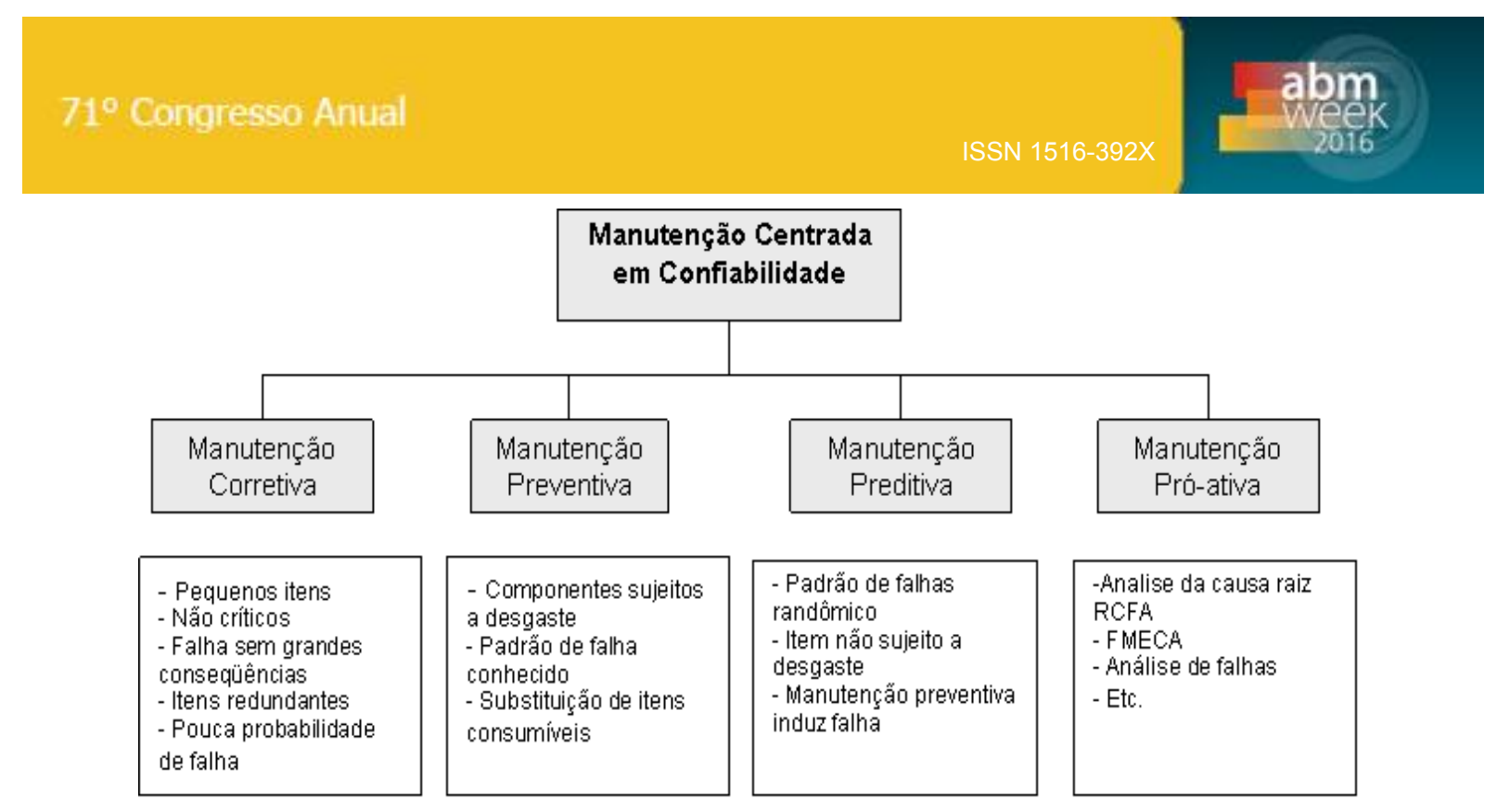

Figura 1. Tarefas de um programa de Manutenção Centrada em Confiabilidade [8]

Toda vez que uma necessidade de manutenção é gerada deve-se levar em consideração que mais cedo ou mais tarde esse componente precisará, na maioria dos casos, ser substituído ou reparado. Dessa análise surge a necessidade de se manter sobressalentes. A compra desses sobressalentes deve passar por uma criteriosa avaliação, pois na maioria das vezes a necessidade do sobressalente não será imediata. A correta definição de qual o melhor momento para a compra desses sobressalentes e fator fundamental para o resultado da empresa, mesmo sabendo através dos estudos de RCM que o sobressalente é crítico.

As Linhas de Tesoura e de Acabamento, fruto do trabalho, tiveram recentemente seus planos de manutenção e inspeção revisados conforme metodologia RCM, onde foi possível otimizar os planos e identificar os sobressalentes faltantes para a linha.

\subsection{Modelo para priorização dos sobressalentes críticos}

Uma vez identificada a necessidade de algum sobressalente crítico se faz necessária à priorização da compra, ou seja, uma avaliação criteriosa da necessidade de aquisição imediata do sobressalente, nos próximos 12 meses ou acima desse prazo. Essa avaliação é realizada em 4 (quatro) etapas principais, Figura 2.

\subsubsection{Definição de criticidade dos equipamentos}

O ponto de partida é a definição da criticidade dos equipamentos onde os sobressalentes serão montados. A criticidade é determinada de forma padronizada seguindo 8 (oito) fatores de falha (Influência na segurança, na produção, na qualidade do produto, no meio ambiente, existência de stand by, taxa de falhas, recuperação da produção após reparo e custo). Todos os equipamentos deverão ter sua criticidade definida em função do cenário de produção mais atual, e ser revisado sempre que necessário, ou seja, sempre que o cenário de produção for modificado e/ou as condições de trabalho que o equipamento está submetido for modificada (regime de trabalho, severidade, carga, temperatura etc.). Toda avaliação de criticidade deverá ser realizada por uma equipe multidisciplinar [9]. 

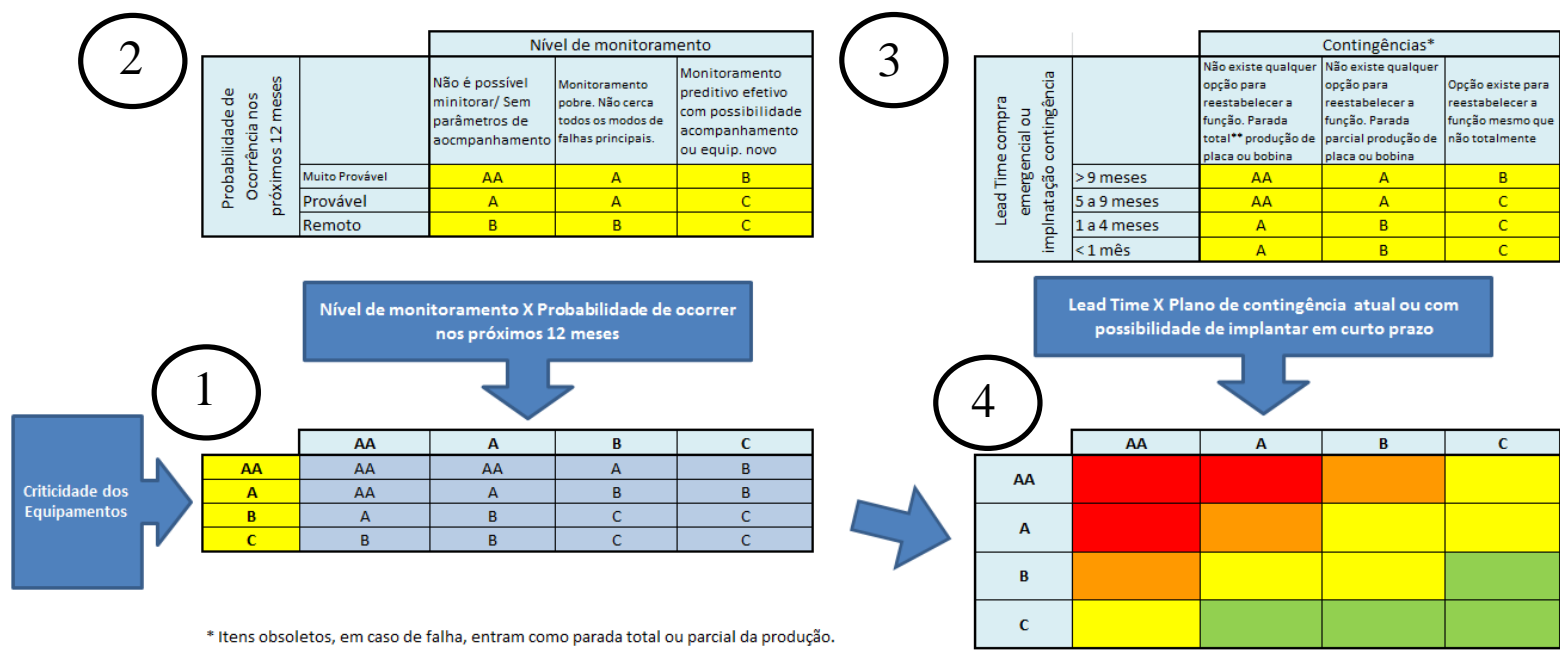

* Itens obsoletos, em caso de falha, entram como parada total ou parcial da produçãa. ** Acima de $60 \%$ de perda de produção de placa ou bobina considerar parada tota.

Figura 2. Modelo para priorização de sobressalentes críticos.

Então, após a identificação da criticidade do equipamento onde o sobressalente será montado, será possível colocar essa informação para compor o eixo vertical abaixo, Figura 3.

\begin{tabular}{|c|c|c|c|c|c|}
\hline \multirow{5}{*}{$\begin{array}{l}\text { Criticidade dos } \\
\text { Equipamentos }\end{array}$} & & AA & A & B & $\mathrm{C}$ \\
\hline & AA & AA & AA & A & $\mathrm{B}$ \\
\hline & A & AA & A & B & B \\
\hline & B & $\mathrm{A}$ & B & $\mathrm{C}$ & $\mathrm{C}$ \\
\hline & C & B & B & $\mathrm{C}$ & $\mathrm{C}$ \\
\hline
\end{tabular}

Figura 3. Identificação da criticidade do equipamento.

\subsubsection{Definição da probabilidade de ocorrência de falhas e nível de monitoramento}

A segunda etapa é a identificação qualitativa da probabilidade de ocorrência de alguma falha no equipamento que necessitará do sobressalente em questão com visão dos próximos 12 meses versus a identificação do nível de monitoramento atual do equipamento ou componente que será substituído pelo sobressalente em questão, Figura 4. As diversas possibilidades possíveis irão gerar combinações "AA", "A", "B" ou "C" que irá compor o eixo horizontal abaixo, Figura 5.

$\mathrm{O}$ cruzamento desses dados com a criticidade definida no item 4.2.1 poderá gerar diversas combinações "AA", "A", "B" ou "C" que irá compor o eixo vertical final de definição de priorização de sobressalentes críticos, Figura 6. 


\begin{tabular}{|c|c|c|c|c|}
\hline & \multicolumn{3}{|c|}{ Nível de monitoramento } \\
\hline \multirow{4}{*}{ 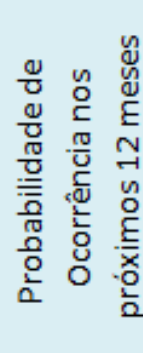 } & & $\begin{array}{l}\text { Não é possivel } \\
\text { minitorar/Sem } \\
\text { parâmetros de } \\
\text { aocmpanhamento }\end{array}$ & $\begin{array}{l}\text { Monitoramento } \\
\text { pobre. Não cerca } \\
\text { todos os modos de } \\
\text { falhas principais. }\end{array}$ & $\begin{array}{l}\text { Monitoramento } \\
\text { preditivo efetivo } \\
\text { com possibilidade } \\
\text { acompanhamento } \\
\text { ou equip. novo }\end{array}$ \\
\hline & Muito Provável & AA & A & B \\
\hline & Provável & A & A & $\mathrm{C}$ \\
\hline & Remoto & B & B & $\mathrm{C}$ \\
\hline
\end{tabular}

Figura 4. Identificação da Probabilidade de Ocorrência versus Monitoramento.

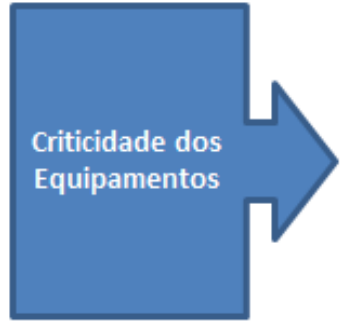

\begin{tabular}{|c|c|c|c|c|}
\cline { 2 - 5 } \multicolumn{1}{c|}{} & AA & A & B & C \\
\hline AA & AA & AA & A & B \\
\hline A & AA & A & B & B \\
\hline B & A & B & C & C \\
\hline C & B & B & C & C \\
\hline
\end{tabular}

Figura 5. Identificação da Probabilidade de Ocorrência versus Monitoramento.

\begin{tabular}{|c|c|c|c|c|}
\cline { 2 - 5 } \multicolumn{1}{c|}{ AA } & A & B & C \\
\hline AA & & & & \\
\hline A & & & & \\
\hline B & & & & \\
\hline C & & & & \\
\hline
\end{tabular}

Figura 6. Composição final do eixo vertical para priorização de sobressalentes críticos.

\subsubsection{Definição do lead time e nível de contingência}

Tempo de ressuprimento em gestão de sobressalentes é o tempo necessário para que o sobressalente percorra todas as etapas de um processo de compra, do início até o fim. No modelo desenvolvido devemos considerar, para itens reparáveis, o tempo total de reparo (desde a perda da função do componente, passando por todo o reparo e retorno ao equipamento), ou o tempo que for menor entre comprar e reparar.

A terceira etapa é a identificação do tempo de ressuprimento emergencial (lead time) do item sobressalente ou tempo de reparo, se o item for reparável (Deve-se considerar o menor tempo entre as duas opções) versus a existência ou não de algum plano de contingência que possibilite o reestabelecimento da função do equipamento mesmo que parcialmente, Figura 7. 


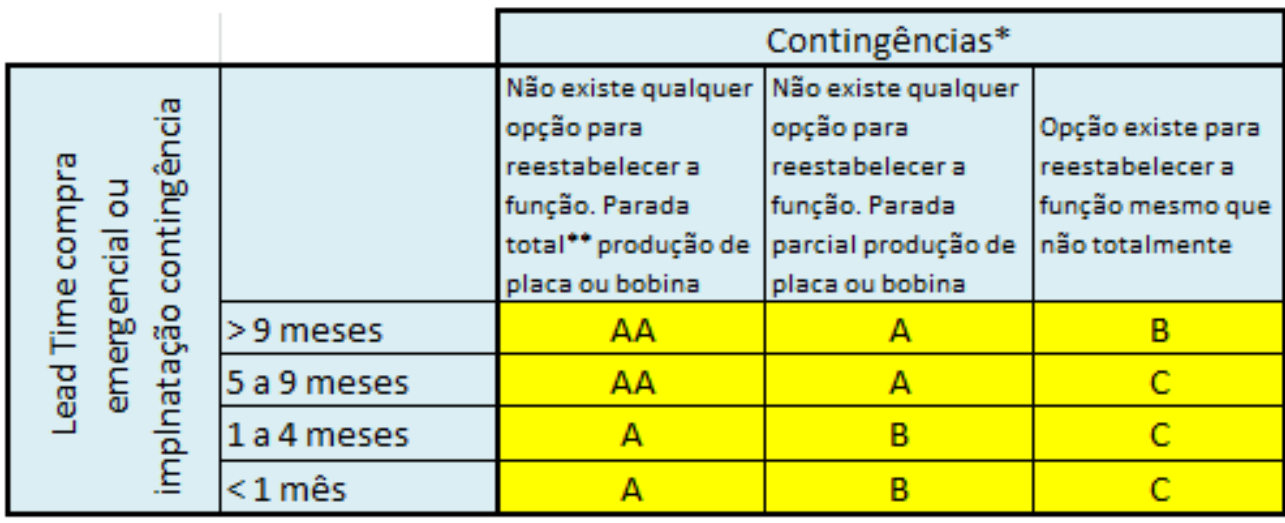

Figura 7. Identificação do lead time emergencial versus Contingências.

O cruzamento desses dados poderá gerar diversas combinações "AA", "A", "B" ou "C" que irá compor o eixo horizontal final de definição de priorização de sobressalentes críticos, Figura 8.

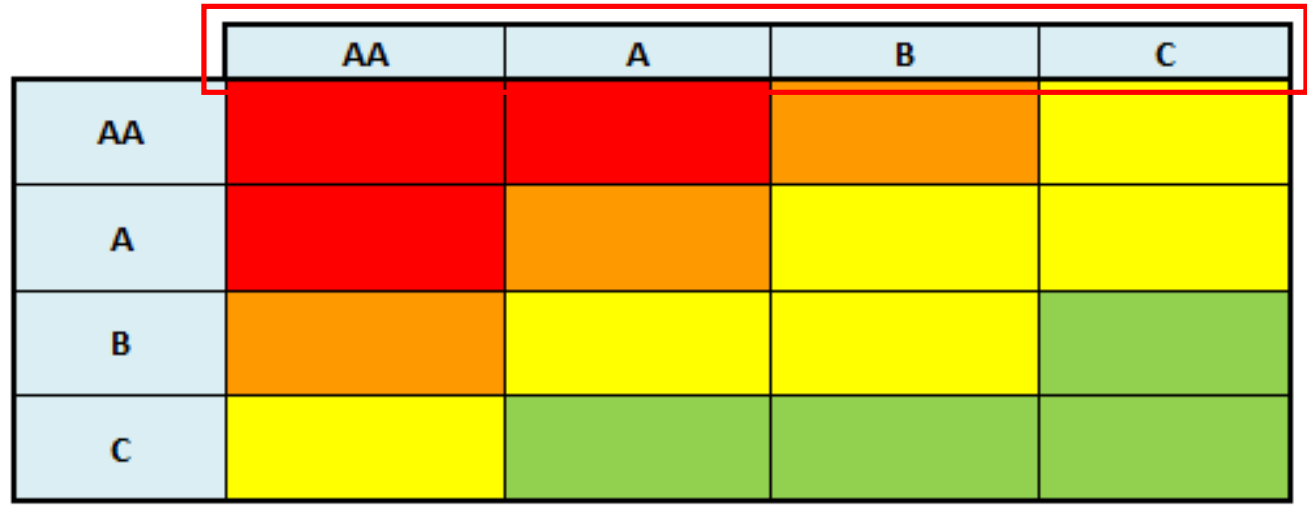

Figura 8. Composição final do eixo vertical para priorização de sobressalentes críticos.

Logo, na última etapa, o sobressalente em análise ficará classificado em quatro faixas distintas:

- Vermelha: Sobressalente deverá ser adquirido imediatamente. Compra indispensável. Realizar compra emergencial.

- Laranja: Sobressalente com compra recomendável nos próximos 12 meses. Incluir no orçamento anual.

- Amarela: Sobressalente deverá ser monitorado nos próximos 12 meses, realizando nova avaliação trimestral.

- Verde: Sobressalente não deverá ser adquirido nos próximos 12 meses. Realizar nova avaliação após 12 meses.

As faixas são qualitativas, ou seja, qualquer posição dentro da mesma cor de faixa possui a mesma importância e deverá ser analisado da mesma forma.

\subsection{Modelo para reclassificação dos sobressalentes em Y00, Y01, Y02 e Y03}

Outro ponto importante é a correta classificação dos sobressalentes de acordo com o "Índice de falta e segurança do material" Y00, Y01, Y02 e Y03. A ArcelorMittal Tubarão não possui um critério claro e bem definido. Devido aos milhares de itens de sobressalentes em estoque atualmente na ArcelorMittal Tubarão, foi prezado pela 
elaboração de um modelo de avaliação mais simples e prático possível. Essa avaliação é realizada em 3 (três) etapas principais, Figura 9.
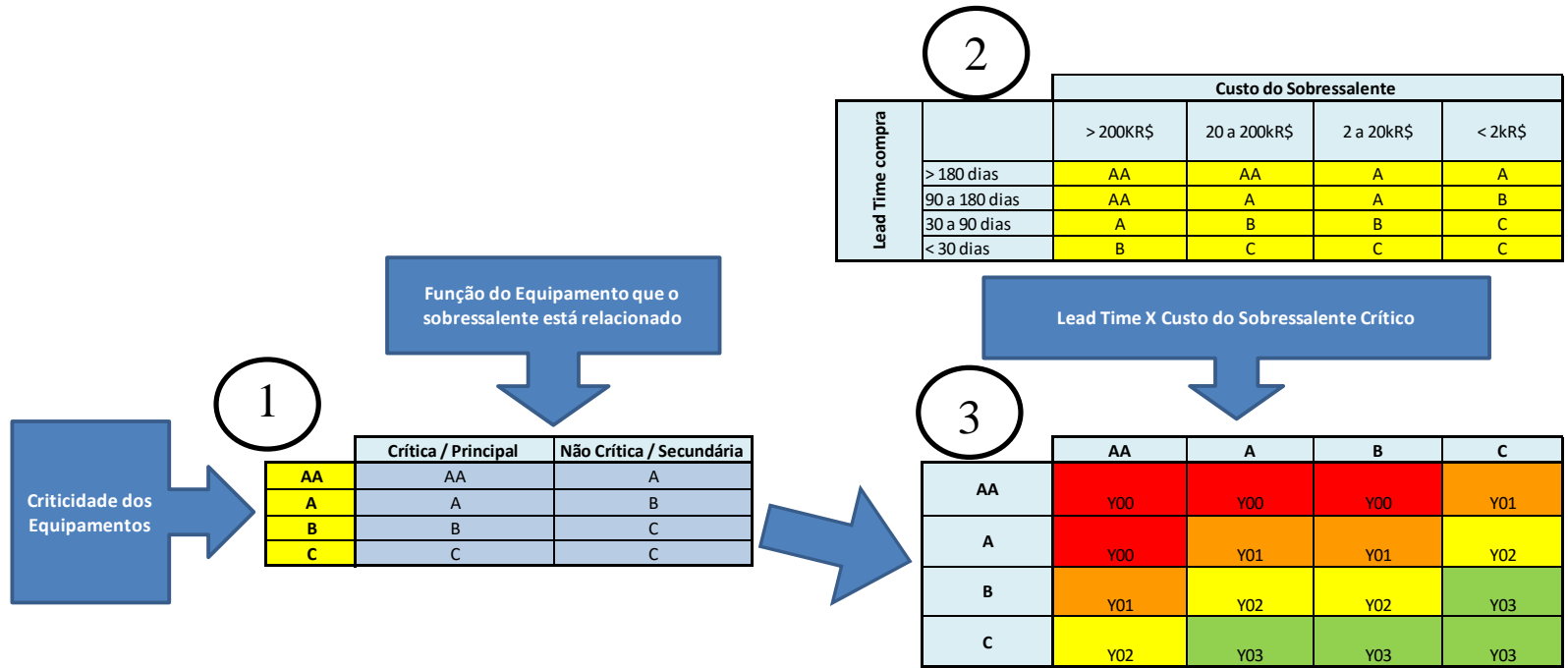

Figura 9. Modelo para reclassificação dos sobressalentes em Y00, Y01, Y02 e Y03.

\subsubsection{Definição de criticidade dos equipamentos e função associada}

O ponto de partida aqui também é a definição da criticidade dos equipamentos onde os sobressalentes serão montados, conforme descrito no item 2.2.1. Se a função do equipamento a qual o sobressalente em questão está associado é não crítica ou uma função secundária ocorre uma redução da criticidade para análise do sobressalente em questão, Figura 10.

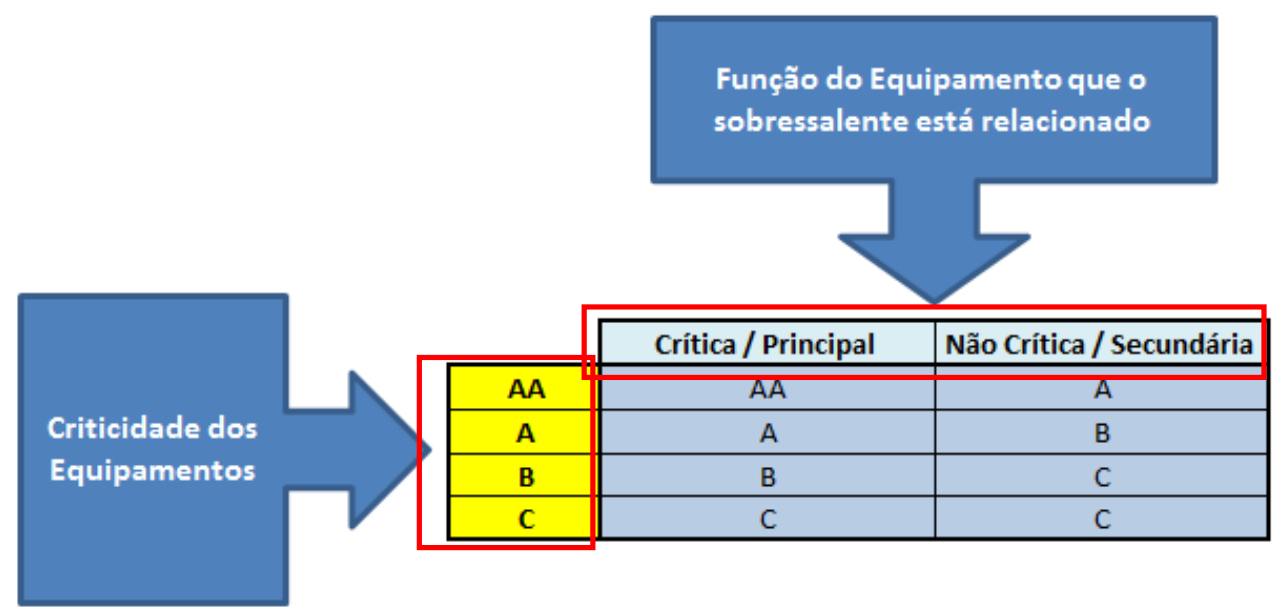

Figura 10. Identificação da criticidade do equipamento e função associada.

O cruzamento desses dados poderá gerar diversas combinações "AA", "A", "B" ou "C" que irá compor o eixo vertical final do modelo de reclassificação de sobressalentes, Figura 11. 


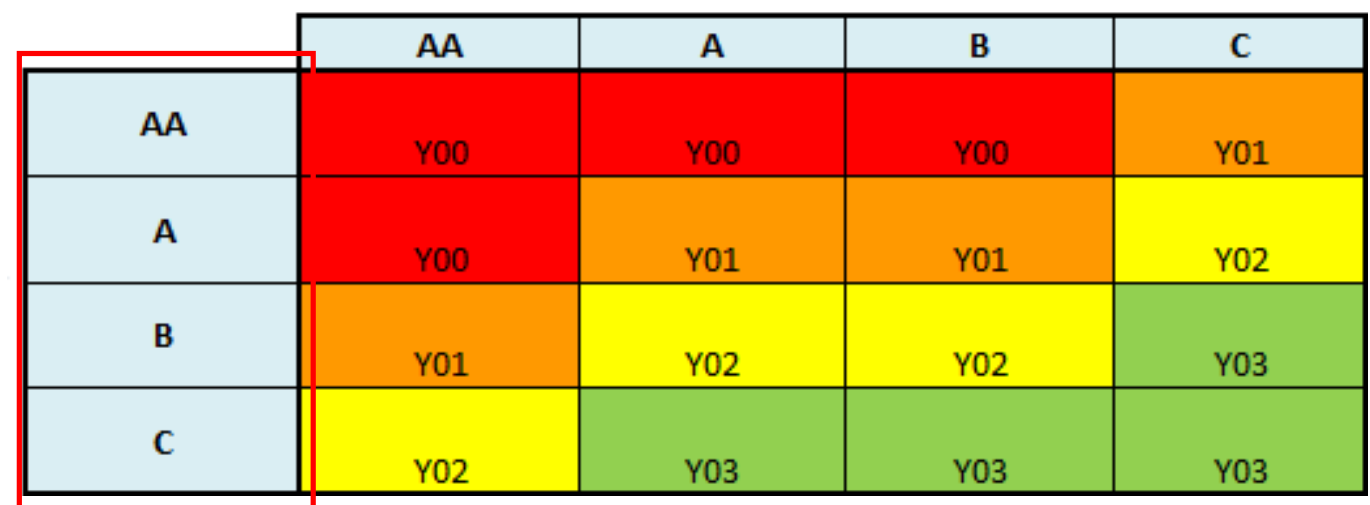

Figura 11. Composição final do eixo vertical para reclassificação de sobressalentes.

\subsubsection{Definição do lead time e custo associado ao sobressalente}

A segunda etapa é a identificação do lead time do item sobressalente versus o custo do sobressalente que está disponível no sistema SAP (custo de aquisição novo), Figura 12. Nesse caso o tempo de ressuprimento (lead time) não considera o tempo total de reparo para itens reparáveis e sim, somente o tempo de compra de um item de sobressalente. Dessa forma o modelo fica mais simples e conservador visto que em uma eventualidade ainda é possível se realizar o reparo do item (quando reparável) que normalmente possui tempo menor que o de compra, ou realizar uma compra emergencial, que normalmente eleva os custos, porém reduz o tempo de ressuprimento. Da mesma forma, mesmo que o item seja reparável, será considerado o custo de aquisição do item novo, por esse ser mais conservador e já estar disponível no SAP.

\begin{tabular}{|c|c|c|c|c|c|}
\hline & & \multicolumn{4}{|c|}{ Custo do Sobressalente } \\
\hline \multirow{5}{*}{ 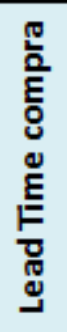 } & & $>200 \mathrm{KR} \$$ & 20 a $200 \mathrm{kR} \$$ & 2 a $20 \mathrm{kR} \$$ & $<2 \mathrm{kR} \$$ \\
\hline & $>180$ dias & AA & AA & A & A \\
\hline & 90 a 180 dias & AA & A & A & $\mathrm{B}$ \\
\hline & 30 a 90 dias & A & B & B & $\mathrm{C}$ \\
\hline & $<30$ dias & B & C & C & C \\
\hline
\end{tabular}

Figura 12. Identificação do lead time de compra emergencial versus Custo do sobressalente.

O cruzamento desses dados poderá gerar diversas combinações "AA", "A", "B" ou "C" que irá compor o eixo horizontal final do modelo de reclassificação de sobressalentes, Figura 13.

\begin{tabular}{|c|c|c|c|c|}
\cline { 2 - 5 } \multicolumn{1}{c|}{} & AA & A & B & C \\
\hline AA & Y00 & Y00 & Y00 & Y01 \\
\hline A & Y00 & Y01 & Y01 & Y02 \\
\hline B & Y01 & Y02 & Y02 & Y03 \\
\hline C & Y02 & Y03 & Y03 & Y03 \\
\hline
\end{tabular}

Figura 13. Composição final do eixo horizontal para reclassificação de sobressalentes. 
Logo, na última etapa, o sobressalente em análise ficará classificado em quatro faixas distintas, incluindo a redefinição da nomenclatura:

- Vermelha: Sobressalente será classificado com Y00 (Estratégico).

- Laranja: Sobressalente será classificado como Y01 (Critico).

- Amarela: Sobressalente será classificado como Y02 (Importante).

- Verde: Sobressalente será classificado como Y03 (Não crítico).

\section{RESULTADOS E DISCUSSÃO}

Aplicando-se o modelo definido no item 2.2 para cada um dos sobressalentes críticos identificados conforme descrito no item 2.1, obtivemos a seguinte classificação, onde a dimensão da esfera representa o custo do sobressalente, Figura 14.

Logo, ficou definido a compra imediata dos sobressalentes 1 e 7 (faixa vermelha), além da recomendação de aquisição do sobressalente 13(faixa laranja) nos próximos 12 meses (durante o ano de 2016 nesse caso). Os sobressalentes 3, 4, 8 e 9 (faixa amarela) não deverão ser adquiridos e serão monitorados e reavaliados trimestralmente. Já os sobressalentes 2, 5, 6, 10, 11 e 12 (faixa verde) não deverão ser adquiridos e serão reavaliados após 12 meses.

Todo o processo de avaliação e monitoramento periódico é conduzido pelo Engenheiro de Confiabilidade (função recém-criada) da área em questão envolvendo equipes multidisciplinares.

Tal análise reduziu a necessidade de orçamento para compra de sobressalentes críticos para 2016 de $5.646 \mathrm{kR} \$$ para $1.590 \mathrm{kR} \$$. Essa diferença de $4.056 \mathrm{kR} \$$ garante maior fluxo de caixa livre - FCF (Free Cash Flow) da ArcelorMittal Tubarão, visto que a variação de estoque a maior entra reduzindo o EBITDA (Lucros antes de juros, impostos, depreciação e amortização) no cálculo do FCF.

\section{Criticidade Sobressalentes visão 2016}

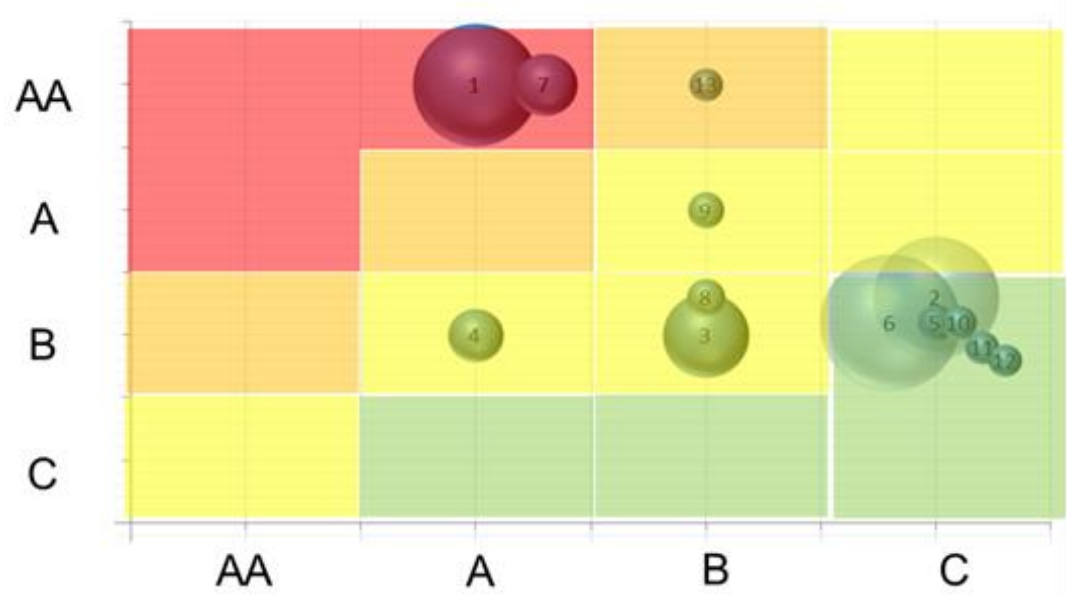

Figura 14. Priorização dos novos sobressalentes críticos do LTQ, LA e LT.

Aplicando-se o modelo definido no item 2.3 para reclassificação dos 813 itens sobressalentes da Linha de Acabamento e Linha de Tesoura obtivemos o seguinte resultado, Figura 15: 
- Migração de grande volume de itens sobressalentes classificados como Y03 (não crítico) para outras categorias.

- Como era de se esperar, somente 8 (oito) itens de sobressalente ficaram como Y00 (estratégico) após análise.

- Os 12 (doze) itens de sobressalente que não tinham classificação atribuída foram reclassificados.

- 270 itens $(33,2 \%)$ foram classificados como Y03 (Não crítico).

Antes da Análise - LA/LT - 813 itens

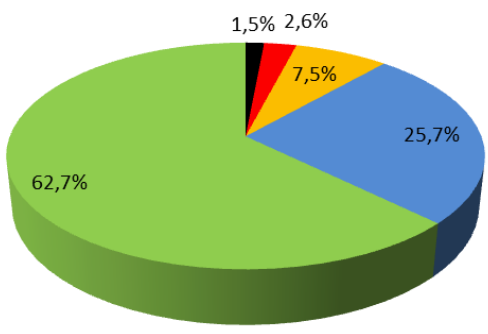

Após Análise - LA/LT - 813 itens

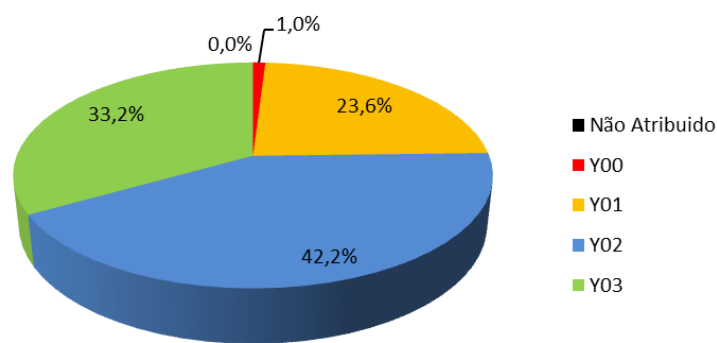

Figura 15. Reclassificação dos itens sobressalentes da Linha de acabamento e Linha de Tesoura Percentual em volume.

Verificando o antes e depois com foco de valor dos itens sobressalentes, obtivemos o seguinte resultado, Figura 16.

- Como era de se esperar os 8 (oito) itens de sobressalentes classificados como Y00 (estratégico) correspondem a $15 \%$ do valor total dos sobressalentes analisados.

- Grande oportunidade para tratamento dos itens de sobressalente classificados como Y03 (não crítico), que correspondem a 14,8\% do valor total ou $\mathrm{kR} \$ 790$.

- Necessidade de maior cuidado na estocagem e manutenção dos 8 (oito) itens de sobressalente reclassificados como Y00 (estratégico), conforme descrito no item 4.4.

Antes da Análise - LA/LT - 5.355kR\$

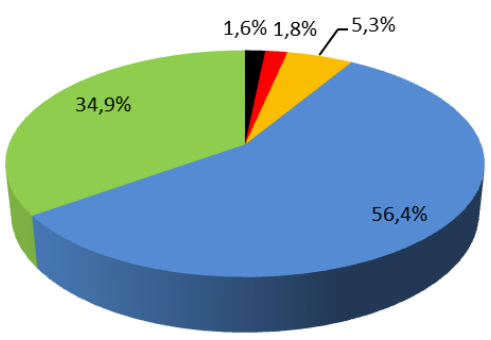

Após Análise - LA/LT - 5.355kR\$

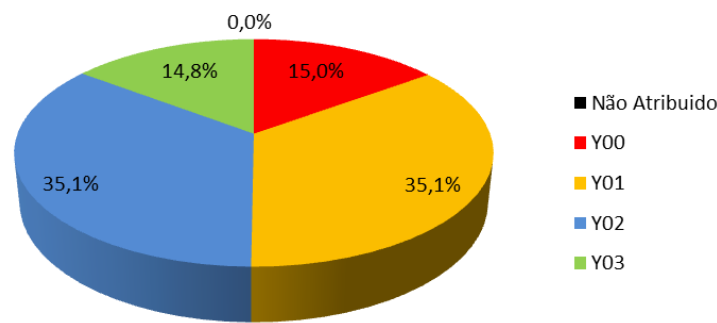

Figura 16. Reclassificação dos itens sobressalentes da Linha de acabamento e Linha de Tesoura Percentual em valor.

A grande oportunidade de redução de custos com essa nova metodologia implantada para a gestão de estoques da Linha de Acabamento e Linha de Tesoura 
está no gerenciamento dos itens sobressalentes classificados como Y03 (14,8\% do total analisado), os sobressalentes definidos como não críticos (Y03), em situação ideal deveriam ter o estoque zerado, salvo itens de alto consumo. Esse "consumo" pode ser verificado através do tempo de permanência no estoque, Figura 17.

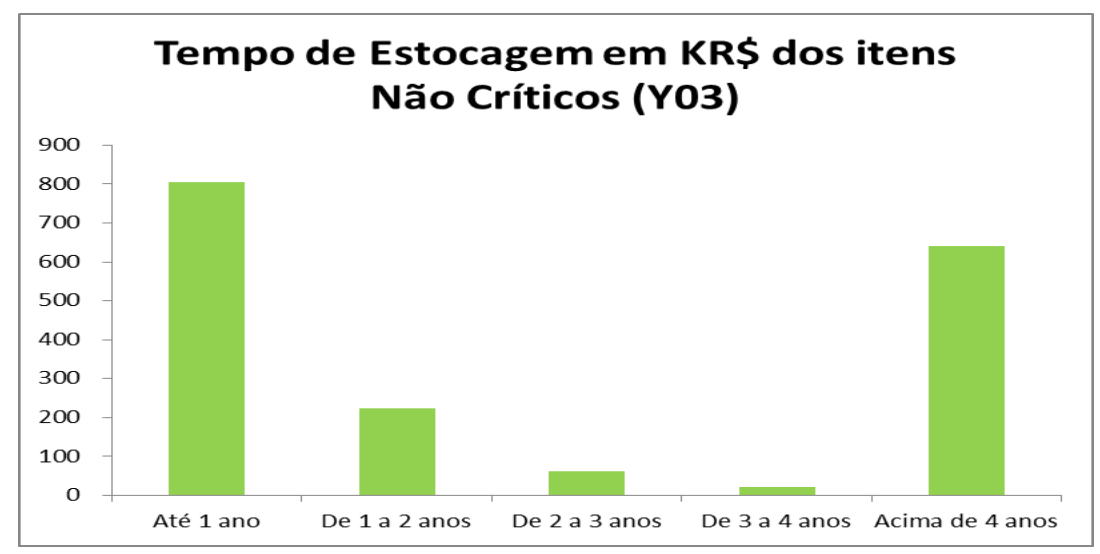

Figura 17. Reclassificação dos itens sobressalentes da Linha de Acabamento e Linha de Tesoura

Para os itens Y03 com permanência superior a 1 (um) ano no estoque deve-se bloquear novas compras e tomar uma das medidas abaixo:

1. Ceder o item sobressalente para alguma empresa do grupo que esteja precisando. Essa ação não penaliza o resultado EBITDA da empresa e aumenta o FCF.

2. Realizar a venda do item de sobressalente, sendo que o valor mínimo de venda deve ser maior ou igual ao valor presente líquido do item considerando:

Onde;

$$
V_{p}=\frac{V_{f}}{(1+i)^{n}}
$$

$V_{p}=$ Valor mínimo para a venda do sobressalente Y03 em questão.

$\mathrm{n}=$ tempo em anos estimado que esse sobressalente ficará parado no estoque.

$V_{f}=$ Valor do item sobressalente, que pode ser utilizado o que está atualmente no SAP, pois esse só vai se alterar se entrar outro item sobressalente no estoque, o que deve ser bloqueado para Y03.

$\mathrm{i}=$ taxa de atratividade (12\% aa).

Essa ação não penaliza o resultado EBITDA da empresa e aumenta o FCF.

3. Realizar a utilização do item sobressalente na ArcelorMittal Tubarão sem repor esse estoque. Em hipótese alguma o sobressalente deve ser consumido sem real necessidade levantada pela área de manutenção, com o intuito de se reduzir o estoque. Essa ação não penaliza o resultado EBITDA da empresa e aumenta gradativamente o FCF. 


\section{CONCLUSÃO}

A aplicação de modelos simples para a gestão de sobressalentes trouxe a correta identificação da necessidade e uma redução de $\sim 4 \mathrm{mR} \$$ de necessidade de capital em 2016 para compra de sobressalentes o que garante maior fluxo de caixa livre.

A reclassificação dos 813 itens sobressalentes realizados como projeto piloto nos indicou um potencial grande de redução de estoques que no primeiro momento estarão focados nos itens classificados como de baixa criticidade (Y03) e com tempo de estoque superior a 4 anos perfazendo um total de $\sim 700 \mathrm{kR} \$$.

Como o valor de estoque das linhas analisadas correspondem a aproximadamente $8 \%$ do total da ArcelorMittal Tubarão, pode ser constatado o grande potencial do uso de larga escala das ferramentas apresentadas.

\section{REFERÊNCIAS}

1 XAVIER, Júlio Nascif. "Gestão para Manutenção Classe Mundial". Tecem tecnologia Empresarial. Belo Horizonte. 2005.

2 KARDEC, Alan e XAVIER, Júlio Nascif. "Manutenção Função Estratégica". 2edição, 1ª Reimpressão 2004. Editora Qualitymark - Rio de Janeiro.

3 GASNIER, D. J. et al. "Gestão de Estoques e Suprimentos na Cadeia de Abastecimento". São Paulo. IMAM, 2007, 1a. Edição.

4 PORTER, Michael E. "Estratégia Competitiva: Técnicas para Análise de Indústrias e da Concorrência”. 18ª Edição. São Paulo-SP: Campus, 1986.

5 WANG, W.; SYNTETOS, A. A. "Spare Parts Demand: Linking Forecasting to Equipment Maintenance Transportation Research". Part E, v.47, p. 1194-1209, 2011.

6 FREITAS, Rafael P. "Controle de Estoque de Peças de Reposição: Revisão da Literatura e um Estudo de Caso". Dissertação de Mestrado. PUC-Rio. 2008.

7 SLATER, P.; LEVITT, J. "Spare Parts Inventory: An Exercise in Risk Management". Disponível em http://www.maintenanceonline.co.uk/article.asp?id=8636. Acesso em 13/12/2015.

8 NASA. "Reliability Centered Maintenance Guide for Facilities and Collateral Equipment". USA. 2000.

9 SODRE, Ricardo e FONSECA, Laudelino. "Plano Diretor de Manutenção e Gestão de Ativos FCSA". 2013. Disponível em http://portalcorp.tubarao.com.br. Acesso 08/01/2016. 